\title{
Vascular Dementia: Potential of Antiplatelet Agents in Prevention
}

\author{
H. Chabriat M.G. Bousser \\ Department of Neurology, Hôpital Lariboisière, Paris, France
}

\section{Key Words}

Vascular dementia, prevention - Antiplatelet treatment

\begin{abstract}
The term 'vascular dementia' ( $\mathrm{VaD}$ ) corresponds to a clinicoradiological syndrome that can be defined with more or less restriction. $\mathrm{VaD}$ can result from: (1) cortical or subcortical ischemic lesions related to the occlusion of large vessels, (2) lacunar infarcts with or without white-matter lesions at the subcortical level related to small-vessel diseases, (3) ischemic lesions related to hypoperfusion or anoxic-ischemic encephalopathy or (4) hemorrhagic lesions. The prevention of $\mathrm{VaD}$ is based on stroke prevention which implies risk factor manipulation and use of antithrombotic drugs among which the most widely used are antiplatelet drugs. The efficiency of these drugs to prevent cognitive impairment and dementia is not proven. Prospective studies are needed to investigate their potential in patients at risk of $\mathrm{VaD}$ : after ischemic stroke, in the presence of cognitive impairment of vascular origin or when MRI shows 'silent' ischemic white-matter lesions and/or infarcts.
\end{abstract}

Copyright $\odot 2006$ S. Karger AG, Basel

\section{Definition and Epidemiology}

The definition of vascular dementia $(\mathrm{VaD})$ remains a difficult issue and is still debated. The term 'vascular dementia' is vague and does not represent a unique patho- physiological entity. Actually, VaD corresponds to a clinicoradiological syndrome that can be defined with more or less restriction. Several groups or institutions have proposed detailed criteria to define $\mathrm{VaD}$. The two most frequently used are the DSM-IV criteria and those of the International Workshop of the National Institute of Neurological Disorders and Stroke (NINDS) and the Association Internationale pour la Recherche et l'Enseignement en Neurosciences (AIREN) [1]. DSM-IV criteria are sensitive but poorly specific (table 1). They can be used in the clinical setting for daily routine. The corresponding

Table 1. DSM-IV criteria for $\mathrm{VaD}$

A1 Memory impairment

A2 One or more of the following cognitive disturbances

a Aphasia

b Apraxia

c Agnosia

d Disturbance in executive functioning

B Cognitive deficits due to criteria A1 and A2 each cause significant impairment in social or occupational functioning and represent a significant decline from a previous level of functioning

C Factors judged to be etiologically related to the disturbance a Focal neurological signs and symptoms

b Laboratory evidence indicative of cerebrovascular disease (e.g. multiple infarctions involving the cortex and underlying white matter)

D Not occurring exclusively during the course of delirium

\section{KARGER \\ Fax +4161306 1234 E-Mail karger@karger.ch} www.karger.com

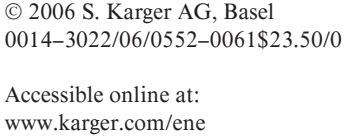

www.karger.com/ene

\section{H. Chabriat}

Department of Neurology, Hôpital Lariboisière

2, rue Ambroise-Paré

FR-75010 Paris (France)

Tel. +33 14995 2597, Fax +33 14995 2596, E-Mail hugues.chabriat@lrb.ap-hop-paris.fr 
Table 2. NINDS-AIREN criteria for the diagnosis of probable $\mathrm{VaD}$

1 Dementia

Impairment of memory

Impairment of memory and $\geq 2$ cognitive domains

Orientation

Attention

Language

Visuospatial functions

Executive functions, motor control and praxis

2 Cerebrovascular disease

Focal signs on neurological examination (hemiparesis, lower facial weakness, Babinski's sign, sensory deficit, hemianopia and dysarthria)

Evidence of relevant cerebrovascular disease by brain imaging (CT)

Large-vessel infarcts

Single strategically placed infarct

Multiple basal ganglia and white-matter lacunes

Extensive periventricular white-matter lesions

Combinations thereof

3 A relationship between the above disorders manifested or inferred by the presence of $\geq 1$ of the following

Onset of dementia within 3 months after a recognized stroke

Abrupt deterioration in cognitive functions

Fluctuating, stepwise progression of cognitive deficits

4 Clinical features consistent with the diagnosis of probable VaD Early presence of a gait disturbance

History of unsteadiness or frequent, unprovoked falls

Early urinary incontinence

Pseudobulbar palsy

Personality and mood changes

5 Features that make the diagnosis of VaD uncertain

Early onset of memory deficit and progressive worsening of memory and other cognitive functions in the absence of focal neurological signs and cerebrovascular lesions on CT or MRI

diagnostic criteria for dementia are focusing on memory impairment associated with alteration of at least one other cognitive domain leading to a significant impairment in social or occupational functioning. No specification concerning the underlying vascular disease is required for diagnosis which explains that one fifth of patients fulfilling the DSM-IV criteria can present without any abnormality on the CT scan. In contrast, the NINDS-AIREN criteria designed for research appear more specific (table 2). Executive dysfunction is a feature of both DSM-IV and NINDS-AIREN definitions; in contrast, visuospatial dysfunction is considered as a criterion only in the latter. Furthermore, the different etiological links with the un-
Table 3. ICD-10 research criteria (DCR-10) for dementia

\section{Dementia}

A Evidence of each of the following

1 Decline in memory (mainly short-term memory)

2 Decline in other cognitive abilities

Deficits in criterion A cause a significant impairment of social functioning

B Absence of clouding of consciousness

C Decline in emotional control or motivation or a change in social behavior

D Symptoms in criterion A have been present $\geq 6$ months Unequal distribution of deficits in higher cognitive functions

Evidence of focal brain damage

Evidence of cerebrovascular disease

Table 4. Hachinski ischemic score

\begin{tabular}{ll}
\hline & Score \\
\hline Abrupt onset & 2 \\
Stepwise deterioration & 1 \\
Fluctuating course & 2 \\
Nocturnal confusion & 1 \\
Relative preservation of personality & 1 \\
Depression & 1 \\
Somatic complaints & 1 \\
Emotional incontinence & 1 \\
History of hypertension & 1 \\
History of strokes & 2 \\
Evidence of associated atherosclerosis & 1 \\
Focal neurological symptoms & 2 \\
Focal neurological signs & 2 \\
\hline
\end{tabular}

derlying vascular disorder are foreseen using the NINDSAIREN criteria [2]. Other definitions of $\mathrm{VaD}$ have been proposed, such as that of the Alzheimer's Disease Diagnostic and Treatment Centers [3], that of the International Classification of Diseases, 10th revision [2] (table 3), or that derived from the Hachinski ischemic score [4]. This score, based on a 13-item scale (table 4), was initially proposed to differentiate multi-infarct dementia caused by multiple ischemic stroke (score $>7$ ) and Alzheimer's disease (AD; score $<4)$. However, it is now well established that the occurrence of multiple cerebral infarcts is not the only pathway to $\mathrm{VaD}$. The occurrence of a single infarct in a strategic brain area can lead to de- 
mentia $[5,6]$. Intracerebral hemorrhages may also have similar consequences. Furthermore, imaging studies have shown that white-matter lesions [7] and so-called silent infarcts [8] could also contribute to the cognitive decline. On the other hand, evidence of brain lesions of vascular origin does not necessarily mean that they are responsible for the cognitive deficit in a given patient. Zekry et al. [9] have recently emphasized that the location, but not the volume, of ischemic or hemorrhagic lesions within the limbic or heteromodal association areas in the brain (cortical or white matter) was playing the primary role in the occurrence of dementia both in $\mathrm{VaD}$ and in mixed dementia which is an association of $\mathrm{VaD}$ and $\mathrm{AD}$.

Finally, the concept itself of $\mathrm{VaD}$ is now reappraised not only because it covers various types of tissue lesions and different underlying vascular disorders, but also because the definition of dementia imposes an artificial categorical distinction on a continuous or stepwise progression of cognitive impairment. This is crucial to understand before establishing strategies for the prevention of cognitive decline [10]. It is also obvious that the risk of dementia in patients with cerebrovascular disease will largely differ according to the presence or absence of associated degenerative brain changes that occur frequently with aging since mixed dementia is probably the most frequent form of dementia [11]. Recently, the term 'vascular cognitive impairment' was proposed to better encompass the whole spectrum of cognitive alterations associated with cerebral lesions of vascular origin [12].

In large European population-based studies, the prevalence of dementia is $6.4 \%$ in subjects aged over 65 years [13], 4.4\% for $\mathrm{AD}$ and $1.6 \%$ for $\mathrm{VaD}$ [14]. The prevalence of $\mathrm{VaD}$ increases considerably with age, from $0.3 \%$ between 65 and 69 years to $5.2 \%$ at the age of 90 years [14]. In the Rotterdam study, a large population-based study of 7,046 persons aged more than 55 years who were free of dementia at baseline, 395 new cases of dementia were observed after a mean follow-up of 5.7 years including 293 cases of $\mathrm{AD}$ and 57 cases of $\mathrm{VaD}$. The corresponding incidence of $\mathrm{VaD}$ was estimated at 1.5 per 1,000 personyears and was found lower in women than in men (ratio: 0.57) [15]. Similar results were observed in other large cohorts [16]. Thus, the incidence of $\mathrm{VaD}$, as well as that of stroke, is higher in men whereas the prevalence is higher in women [14] because of their 10-year-longer life expectancy.

The increasing number of demented patients (particularly in well-developed countries) represents an important challenge for health care and social support systems. However, little is known concerning the actual cost for
Table 5. Main causes of stroke (modified from Albers et al. [77])

\begin{tabular}{lc}
\hline & Percent \\
\hline Primary hemorrhage & $\mathbf{1 5}$ \\
Ischemic stroke & $\mathbf{8 5}$ \\
Atherothromboembolism & 20 \\
Intracranial small-vessel diseases & 25 \\
Cardiac source of embolism & 20 \\
Cerebral venous thrombosis & 0.5 \\
Miscellaneous unusual causes & \\
$\quad$ (e.g. dissection, arteritis, drug abuse) & 5 \\
Undetermined cause & 30 \\
\hline
\end{tabular}

society of this tremendous issue [17]. At the caregiver level, the burden of dementia has different aspects: general strain, isolation, disappointment or emotional disturbances [18]. Interestingly, the relatives of patients with VaD might be more stressed by the disturbing behavior and the memory impairment of the patients whereas, for $\mathrm{AD}$, the most stressful part of caring is the social behavior [19].

\section{Main Causes and Risk Factors}

$\mathrm{VaD}$ results from ischemic and/or hemorrhagic cerebral lesions that can manifest as different clinical syndromes (table 5). Most often, four categories of lesions can be detected on MRI or CT scan in VaD patients: (1) cortical or subcortical ischemic lesions related to the occlusion of large vessels, (2) lacunar infarcts with or without white-matter lesions at the subcortical level related to small-vessel diseases, (3) ischemic lesions related to hypoperfusion or anoxic-ischemic encephalopathy or (4) hemorrhagic lesions [20].

The occlusion of large vessels secondary to atherothrombosis or caused by cardiogenic emboli can lead to the so-called multiple-infarct dementia related to the accumulation of large infarcts at the cortical and/or subcortical level [4]. In some cases, only a single infarct in functionally critical areas of the brain (angular gyrus, thalamus, basal forebrain or territory of the posterior or anterior cerebral artery) can lead to a 'strategic-infarct dementia' [6]. Atrial fibrillation is a major cause of stroke; in the Rotterdam study, dementia was more than twice as common in subjects with atrial fibrillation than in those without [21]. Elsewhere, case-control or cross-sectional studies suggested that atrial fibrillation is associ- 
ated with cognitive impairment even in the absence of stroke events possibly through the occurrence of silent cardioembolic infarcts [22, 23].

Small-vessel diseases of the brain lead to a large spectrum of lesions in the subcortical regions supplied by the perforating arteries: lacunar infarcts (small deep infarcts of diameter less than $15 \mathrm{~mm}$ ), white-matter demyelination and rarefaction (called 'leukoaraiosis') and microhemorrhages. The contribution of these different lesions in the cognitive deficit largely varies according to their type (complete or incomplete infarcts, demyelination), extent and location [9]. The most frequent small-vessel disease of the brain is the hypertensive arteriosclerotic angiopathy, mainly detected in elderly patients. In the majority of cases, the subcortical ischemic lesions are associated with more or less severe degenerative lesions (as observed in $\mathrm{AD}$ ) in so-called mixed dementias. Only in few cases are the widespread deep infarcts and diffuse white-matter lesions isolated and responsible for a 'pure VaD' previously called 'Binswanger's disease' [24]. The term 'subcortical ischaemic VaD' is now preferred for this category of dementia related to small-vessel diseases in general [20], a group including hereditary small-vessel diseases such as 'cerebral autosomal dominant arteriopathy with subcortical infarcts and leukoencephalopathy' [25] caused by mutation of the Notch3 gene on chromosome 19 [26].

Ischemic lesions related to hypoperfusion of the brain are rare. They include the diffuse anoxic-ischemic encephalopathy [27] secondary to acute diffuse cerebral hypoperfusion (after cardiac arrest for example) and focal lesions in cerebral regions of selective vulnerability promoted by the presence of severe atherothrombotic stenosis or occlusion of large arteries [28].

Finally, the accumulation of hemorrhagic lesions is another cause of $\mathrm{VaD}$. Hypertension modifying the wall of the perforating arteries of the brain is the most frequent cause of deep cerebral hematomas in the elderly and thus of $\mathrm{VaD}$ due to hemorrhagic lesions. Other risk factors include high alcohol intake and the male sex according to Ariesen et al. [29]. In contrast, severe forms of amyloid angiopathy predominating in leptomeningeal and short cortical perforating arteries are mainly responsible for recurrent cortical hemorrhages in elderly patients that can also lead to $\mathrm{VaD}$ or mixed dementia [30]. Familial forms of amyloid angiopathy secondary to different mutations in several genes (Amyloid Precursor Protein, protein Bri, Gelsolin, Cystatin C) are extremely rare [31].

The relationships between vascular risk factors and dementia have been demonstrated in different cohorts, most frequently without distinction between $\mathrm{VaD}$, mixed dementia and AD. Most data from longitudinal studies emphasized the crucial role of hypertension in the occurrence of dementia [32, 33]. In a large cohort of 3,703 Japanese-American men included in the Honolulu Heart Program, the risk of dementia was increased by a factor of 4 for a diastolic blood pressure above $90 \mathrm{~mm} \mathrm{Hg}$ and by 4.8 for a systolic blood pressure above $160 \mathrm{~mm} \mathrm{Hg}$ by comparison with normotensive subjects. In France, in a longitudinal population-based study of 1,373 French elderly individuals (EVA study), the risk of cognitive decline after 4 years (defined as a 4-point drop on the MiniMental State Examination, MMSE) was 4.3 times greater in patients with high blood pressure measured at baseline. This risk was increased by 6 -fold in untreated hypertensive patients at the 2-year assessment [32].

The risk of $\mathrm{VaD}$ related to the lipid profile has been investigated longitudinally only in a few studies. Moroney et al. [34] found that the risk of dementia with stroke was weakly associated with high levels of low-density lipoprotein cholesterol in their large prospective study but not in their cross-sectional analysis. Elsewhere, different authors reported that a low level of high-density lipoprotein cholesterol was associated with an increased risk of $\mathrm{VaD}$ [35-37]. In the longitudinal study performed by Reitz et al. [37], the impact of drugs used to reduce the cholesterol level on the risk of dementia was not significant. Prospective studies are warranted to assess the promising effects of statins on the risk of dementia.

Smoking was found to increase the risk of both $\mathrm{VaD}$ and AD. In the recent study of Juan et al. [38] of 2,820 participants aged 60 years, the relative risk of $\mathrm{VaD}$ was found to be nonsignificant in past smokers but at 1.98 in current smokers. Interestingly, Ott et al. [39] have recently reported that the MMSE score of persons who never smoked on average declined 0.03 points/year but that this decline was 0.03 and 0.13 points greater in former and current smokers.

Hyperhomocysteinemia was previously associated with $\mathrm{VaD}$ in different case-control or cross-sectional studies [40, 41]. Various data suggest that hyperhomocysteinemia is mostly associated with small-vessel diseases, white-matter lesions or silent deep infarcts in the brain $[42,43]$. Longitudinal studies are lacking to estimate the actual risk of dementia related to increased homocysteinemia.

The recent data from the Women Health Initiative showed that estrogen + progestin therapy increased the risk for dementia in postmenopausal women aged 65 years or older, also possibly by increasing the risk of vascular insults to the brain [44]. 
A decreased risk of dementia or cognitive decline was reported with a moderate consumption of wine both in the Paquid study [45] and in the EVA cohort as observed in general for vascular diseases. This protective role of moderate alcohol consumption (1-6 drinks weekly) has recently been confirmed in a nested case-control study of patients recruited from the Cardiovascular Health Study cohort [45]. Diabetes is slightly increasing the risk of dementia in general $[46,47]$ with a relative risk estimated at 1.66 by Leibson et al. [46] for both $\mathrm{AD}$ and $\mathrm{VaD}$.

Besides these modifiable vascular risk factors, numerous markers of the cardiovascular risk have recently been identified such as biochemical markers (e.g. C-reactive protein, fibrinogen, interleukin 6), morphological markers (e.g. intima-media thickness, coronary calcifications, silent cerebral infarcts) and genetic markers (e.g. phosphodiesterase) [48]. Only a few of them have been studied in relation with $\mathrm{VaD}$; they are mostly markers of early atherosclerosis.

In the Atherosclerosis Risk in Communities cohort, a large biracial, longitudinal investigation of 10,963 individuals, no significant relationship was detected between the carotid intima-media thickness and the risk of cognitive decline measured 6 years after the entry in the study [49]. In contrast, the severity of atherosclerosis (measured with indicators such as wall thickness, plaques, ratio of ankle-to-brachial systolic blood pressure) was found to be strongly associated with both $\mathrm{VaD}$ and $\mathrm{AD}$ in the Rotterdam study [50]. This is possibly related to the increased risk of ischemic stroke, silent infarcts and white-matter lesions in the presence of atherosclerosis. In the Framingham study, the occurrence of a first stroke doubled the risk of dementia at 10 years [8]. Recently, silent brain infarcts (asymptomatic lacunar infarcts on MRI) were found to double the risk of dementia at 3.6 years in the elderly patients included in the Rotterdam study [8]. The severity of aortic [51], carotid [52] and vertebral [53] atherosclerosis was previously shown to increase the risk of ischemic stroke, which is further amplified when atherosclerosis involved the intracranial arteries [53, 54]. The intima-media thickness and plaques at the carotid level are associated with the occurrence of silent cerebral infarcts on MRI [55]. Finally, in the EVA cohort, the presence of carotid plaques at baseline was associated with severe MRI white-matter hyperintensities observed 4 years after the entry in the study after adjusting for age, gender and hypertension [56].

Of note, the Apolipoprotein E4 gene allele which increases the risk of $\mathrm{AD}$ does not seem associated with the risk of $\mathrm{VaD}$ [57].

Vascular Dementia and Antiplatelet Agents

\section{Treatment}

Therapeutic options in patients with $\mathrm{VaD}$ are scarce. Various molecules have been evaluated to improve the cognitive deficit of patients with established VaD. The results obtained with vasodilators, nootropics and antioxidants or propentofylline in patients with $\mathrm{VaD}$ were disappointing. The beneficial effect of the calcium antagonist nimodipine initially detected in a subgroup of patients with subcortical $\mathrm{VaD}$ [58] has not recently been confirmed by a placebo-controlled study, although a trend for better performances in lexical production and less deterioration on the MMSE was detected in $\mathrm{VaD}$ patients under treatment [59]. Conversely, cholinesterase inhibitors have been found efficient in $\mathrm{VaD}$. Three drugs approved in $\mathrm{AD}$ - donepezil, rivastigmine and galantamine - have been tested in VaD. Donepezil was evaluated in a total of $1,219 \mathrm{VaD}$ patients diagnosed using the NINDS-AIREN criteria in two trials [60, 61]. In both trials, a significant benefit was detected in treated patients with the neuropsychological battery of the AD Assessment Scale cognitive subscale (ADAS-cog) after 24 weeks of treatment. Of interest, the cognitive decline was lower than that usually observed in AD patients during similar studies. In contrast to the mere reduction of cognitive decline obtained with this drug in patients with $\mathrm{AD}$, some improvement of the baseline cognitive status was detected with this molecule in $\mathrm{VaD}$. Galantamine is another acetylcholinesterase inhibitor that also modulates the central nicotinic receptors to increase the cholinergic transmission. In a large trial including both patients with mixed dementia and $\mathrm{VaD}$, galantamine showed greater efficacy than placebo on the ADAS-cog and CIBIC-plus evaluation results [62]. Among patients with $\mathrm{VaD}$, the mean change from baseline of the ADAS-cog was only 2.4 points; $31 \%$ patients under the treatment compared to $23 \%$ under the placebo had their global function improved or maintained at least up to 12 months. Rivastigmine was only evaluated in a small open-label study of patients with subcortical VaD showing some improvement in cognition, caregiver stress and behavior [62].

\section{Prevention}

After the diagnosis of $\mathrm{VaD}$, some data suggest that the use of antiplatelet drugs may be beneficial to the patients. In a retrospective case-notes study, Devine et al. [63] observed that patients with $\mathrm{VaD}$ treated with aspirin discharged from the nonacute patient unit had a longer life 
expectancy and survival than patients without treatment. In a hospital-based cohort of African-American patients with $\mathrm{VaD}$ and $\mathrm{AD}$, Freels et al. [64] also reported that $\mathrm{VaD}$ patients under antiplatelet treatment (or anticoagulation for cardiogenic embolism) were at lower risk of death. Controlled studies are however lacking to show how long the antiplatelet drugs should be administered to patients with $\mathrm{VaD}$. The benefit/risk ratio may greatly vary in $\mathrm{VaD}$ patients according to the risk of hemorrhage which is increased by the presence of silent microhemorrhages on MRI often detected in the presence of diffuse ischemic white-matter lesions, by gait disturbances and falls, or by the lack of optimal control of blood pressure.

The relatively low efficacy of available drugs to improve cognition in patients with $\mathrm{VaD}$ emphasizes the crucial importance of prevention of vascular disorders which may lead to the development of dementia. The prevention of $\mathrm{VaD}$ is thus that of stroke which is based on risk factor manipulation for both ischemic and hemorrhagic stroke and on antithrombotic drugs for ischemic stroke.

\section{Risk Factor Manipulation}

The crucial role of hypertension in the development of dementia was confirmed by recent trials of antihypertensive drugs showing a reduction in the incidence of dementia by blood pressure lowering. The results of the Syst-Eur trial support the hypothesis that the treatment of 1,000 hypertensive patients aged $>60$ years for 5 years would prevent the occurrence of dementia in 19 cases [65]. In the PROGRESS trial, a secondary stroke prevention study [66] designed in hypertensive and nonhypertensive patients with a history of stroke or transient ischemic attack, a flexible regimen based on the angiotensin-converting enzyme inhibitor perindopril with the addition of the diuretic indapamide, was associated with a $34 \%$ risk reduction of dementia after 3.9 years. This effect was observed in association with the decreased risk of stroke under treatment and it was not significant in the absence of stroke recurrence [67]. Such results emphasized that the protective effect of antihypertensive drugs on cognition is probably related to the decreased frequency of cerebral insults.

\section{Antithrombotic Drugs}

In the presence of an identified vascular disorder, the use of antiplatelet drugs appears as the cornerstone of secondary stroke prevention [68]. The efficacy of antiplatelet drugs is largely demonstrated. The overview of 145 randomized trials of aspirin versus placebo clearly showed that the risk of vascular events is significantly re- duced by aspirin in patients with acute or past myocardial infarction, angina, vascular surgery, angioplasty, atrial fibrillation, peripheral vascular diseases and in patients with a history of stroke or transient ischemic attacks with doses ranging from $75 \mathrm{mg}$ to $1 \mathrm{~g}$ [69]. In stroke patients, the reduction risk of cerebral ischemic events with aspirin is between 20 and 30\% [69]. After the occurrence of transient ischemic attack or stroke, the Ticlopidine-Aspirin Stroke Study showed that ticlopidine was slightly more effective than aspirin to prevent stroke with a cumulative event rate at 1 year for nonfatal stroke or death at $6.3 \%$ for patients under treatment and $10.8 \%$ for patients receiving aspirin [70]. However, ticlopidine has been shown to cause neutropenia in $2.4 \%$ treated persons. In the European Stroke Prevention Study, the combination of acetylsalicylic acid and dipyridamole was found to reduce the risk of stroke or death by $24 \%$ in patients with prior stroke or transient ischemic attack [71].

Clopidogrel, a thienopyridine derivative similar to ticlopidine but with a superior effect in animals on adenosine-diphosphate-induced platelet aggregation [72], has been compared to aspirin in the CAPRIE (Clopidogrel vs. Aspirin in Patients at Risk of Ischemic Events) trial. It was the largest prospective evaluation of antiplatelet agents and the first study to include patients with the three main clinical manifestations of atherothrombosis (recent ischemic stroke, recent myocardial infarction or symptomatic peripheral arterial disease). The intention-totreat analysis showed that the relative risk reduction was $8.7 \%$ in favor of clopidogrel from an overall annual event rate of ischemic stroke, myocardial infarction or vascular death, ranging from $5.83 \%$ in the aspirin group to $5.33 \%$ in the clopidogrel group. Most importantly, the safety was comparable to that of aspirin without any increased risk of neutropenia. The results of the CAPRIE study suggest an overall relative risk reduction for stroke of $7.3 \%$ in favor of clopidogrel. Of interest, $59 \%$ of qualifying strokes were atherothrombotic and 40\% lacunar. Furthermore, in patients included after the occurrence of a myocardial infarction, 20\% of first outcome events were strokes; in those who had a symptomatic peripheral arterial disease, this frequency was close to $50 \%$. These results suggest that clopidogrel is actually effective to reduce the risk of stroke not only in patients with a history of transient ischemic attack or ischemic stroke, but also in patients with a recent history of myocardial infarction or with symptomatic peripheral arterial disease. As the reduction of stroke plays a key role to decrease the risk of dementia (both $\mathrm{VaD}$ and mixed dementia), it can be inferred that antiplatelet drugs probably reduce the risk of cognitive de- 
cline. Future trials including the occurrence of dementia or cognitive decline as a primary or secondary end point are, however, necessary to confirm this hypothesis. Such data will be particularly useful in elderly patients for whom the benefit/risk ratio of preventive strategies is regularly questioned.

Results from the Rotterdam study suggest that aspirin use in the elderly may increase the risk of stroke [73], possibly by increasing the risk of cerebral hemorrhage. Consequently, antiplatelet drugs cannot be recommended in the absence of an identified vascular disease to reduce the risk of $\mathrm{VaD}$.

In prevention of stroke, cardiac arrhythmia due to atrial fibrillation and the existence of mechanical prosthetic valves are the only two indications of anticoagulants that have been demonstrated. The negative results of the Warfarin-Aspirin Recurrent Stroke Study trial support the concept that antiplatelet therapy is the preferred option for preventing recurrent ischemic stroke related to atherosclerosis [74].

\section{Conclusion}

$\mathrm{VaD}$ is a major health issue, firstly because it is the second leading cause of dementia either by itself or in association with $\mathrm{AD}$, secondly because its prevalence is rising with the aging of the population, thirdly because of the lack of effective treatment once dementia is estab- lished. There are different varieties of $\mathrm{VaD}$ which are closely linked to the numerous etiopathogenic varieties of ischemic and hemorrhagic stroke.

Given the burden of $\mathrm{VaD}$, its prevention is a crucial health priority. It is based on stroke prevention which implies risk factor manipulation and use of antithrombotic drugs among which the most widely used are antiplatelet drugs. Given the well-established efficacy of antiplatelet drugs, large use of these molecules and good tolerance in stroke prevention, it is likely that they may decrease the risk of $\mathrm{VaD}$. Prospective studies are needed to investigate this potential in future therapeutic trials.

Finally, cognitive impairment and dementia should be considered now as major end points in studies devoted to stroke prevention. In future, the recognition of any vascular cognitive impairment and use of neuroimaging markers in the populations at risk will also be crucial to prevent $\mathrm{VaD}$. In the elderly, a large spectrum of cognitive disturbances appear related to vascular cerebral lesions long before the occurrence of dementia. These lesions are easily detected on MRI. They can be observed even in the absence of stroke, coronary heart disease or peripheral arterial disease. In the general population, white matter lesions and/or 'silent' infarcts have been shown to increase both the risk of stroke and dementia $[8,75,76]$. The benefit of antiplatelet drugs based on these new clinical and MRI markers of vascular disorders remains to be investigated in future large trials.

\section{References}

1 Roman GC, Tatemichi TK, Erkinjuntti T, Cummings JL, Masdeu JC, Garcia JH, Amaducci L, Orgogozo JM, Brun A, Hofman A, et al: Vascular dementia: diagnostic criteria for research studies. Report of the NINDS-AIREN International Workshop. Neurology 1993;43:250-260.

-2 Wetterling T, Kanitz RD, Borgis KJ: Comparison of different diagnostic criteria for vascular dementia (ADDTC, DSM-IV, ICD-10, NINDS-AIREN). Stroke 1996;27:30-36.

$\checkmark 3$ Chui HC, Victoroff JI, Margolin D, Jagust W, Shankle R, Katzman R: Criteria for the diagnosis of ischemic vascular dementia proposed by the State of California Alzheimer's Disease Diagnostic and Treatment Centers. Neurology 1992;42:473-480.

4 Hachinski VC, Lassen NA, Marshall J: Multiinfarct dementia: a cause of mental deterioration in the elderly. Lancet 1974;ii:207-210.
5 Tatemichi TK, Desmond DW, Prohovnik I, Cross DT, Gropen TI, Mohr JP, Stern Y: Confusion and memory loss from capsular genu infarction: a thalamocortical disconnection syndrome? Neurology 1992;42:1966-1979.

6 Tatemichi TK, Desmond DW, Prohovnik I: Strategic infarcts in vascular dementia: a clinical and brain imaging experience. Arzneimittelforschung 1995;45:371-385.

7 Longstreth WT Jr, Manolio TA, Arnold A, Burke GL, Bryan N, Jungreis CA, Enright PL, O'Leary D, Fried L: Clinical correlates of white matter findings on cranial magnetic resonance imaging of 3,301 elderly people. The Cardiovascular Health Study. Stroke 1996;27:12741282.

8 Vermeer SE, Prins ND, den Heijer T, Hofman A, Koudstaal PJ, Breteler MM: Silent brain infarcts and the risk of dementia and cognitive decline. N Engl J Med 2003;348:1215-1222.
-9 Zekry D, Duyckaerts C, Belmin J, Geoffre C, Herrmann F, Moulias R, Hauw JJ: The vascular lesions in vascular and mixed dementia: the weight of functional neuroanatomy. Neurobiol Aging 2003;24:213-219.

10 Sachdev P, Brodaty H: Vascular dementia: an Australian perspective. Alzheimer Dis Assoc Disord 1999;13(suppl 3):S206-S212.

11 Zekry D, Hauw JJ, Gold G: Mixed dementia: epidemiology, diagnosis, and treatment. J Am Geriatr Soc 2002;50:1431-1438.

12 O'Brien JT, Erkinjuntti T, Reisberg B, Roman G, Sawada T, Pantoni L, Bowler JV, Ballard C, DeCarli C, Gorelick PB, Rockwood K, Burns A, Gauthier S, DeKosky ST: Vascular cognitive impairment. Lancet Neurol 2003;2:8998.

13 Ankri J, Poupard M: Prevalence and incidence of dementia among the very old (review). Rev Epidémiol Santé Publique 2003;51:349-360. 
14 Lobo A, Launer LJ, Fratiglioni L, Andersen K, Di Carlo A, Breteler MM, Copeland JR, Dartigues JF, Jagger C, Martinez-Lage J, Soininen $\mathrm{H}$, Hofman A: Prevalence of dementia and major subtypes in Europe: A collaborative study of population-based cohorts. Neurologic Diseases in the Elderly Research Group. Neurology 2000;54:S4-S9.

-15 Ruitenberg A, Ott A, van Swieten JC, Hofman A, Breteler MM: Incidence of dementia: does gender make a difference? Neurobiol Aging 2001;22:575-580.

-16 Hebert R, Lindsay J, Verreault R, Rockwood K, Hill G, Dubois MF: Vascular dementia: incidence and risk factors in the Canadian study of health and aging. Stroke 2000;31:14871493.

17 Wimo A, Winblad B: Economic aspects on drug therapy of dementia. Curr Pharm Des 2004; 10:295-301.

-18 Annerstedt L, Elmstahl S, Ingvad B, Samuelsson SM: Family caregiving in dementia - An analysis of the caregiver's burden and the 'breaking-point' when home care becomes inadequate. Scand J Public Health 2000;28:2331.

-19 Rainer M, Jungwirth S, Kruger-Rainer C, Croy A, Gatterer G, Haushofer M: Family caregivers of patients with dementia: impact of factors of burden. Psychiatr Prax 2002;29:142-147.

-20 Roman GC, Erkinjuntti T, Wallin A, Pantoni L, Chui HC: Subcortical ischaemic vascular dementia. Lancet Neurol 2002;1:426-436.

-21 Ott A, Breteler MM, de Bruyne MC, van Harskamp F, Grobbee DE, Hofman A: Atrial fibrillation and dementia in a population-based study. The Rotterdam Study. Stroke 1997;28: 316-321.

-22 O'Connell JE, Gray CS, French JM, Robertson $\mathrm{IH}$ : Atrial fibrillation and cognitive function: case-control study. J Neurol Neurosurg Psychiatry 1998;65:386-389.

23 Kilander L, Andren B, Nyman H, Lind L, Boberg M, Lithell $\mathrm{H}$ : Atrial fibrillation is an independent determinant of low cognitive function: a cross-sectional study in elderly men. Stroke 1998;29:1816-1820.

24 Babikian V, Ropper AH: Binswanger's disease: a review. Stroke 1987;18:2-12.

-25 Chabriat H, Vahedi K, Iba-Zizen MT, Joutel A, Nibbio A, Nagy TG, Krebs MO, Julien J, Dubois B, Ducrocq X, et al: Clinical spectrum of CADASIL: a study of 7 families. Cerebral autosomal dominant arteriopathy with subcortical infarcts and leukoencephalopathy. Lancet 1995;346:934-939.

-26 Joutel A, Vahedi K, Corpechot C, Troesch A, Chabriat $\mathrm{H}$, Vayssière $\mathrm{C}$, Cruaud $\mathrm{C}$, Maciazek $\mathrm{J}$, Weissenbach J, Bousser MG, Bach JF, Tournier-Lasserve E: Strong clustering and stereotyped nature of Notch3 mutations in CADASIL patients. Lancet 1997;350:15111515.

-27 Hashiguchi S, Mine H, Ide M, Kawachi Y: Watershed infarction associated with dementia and cerebral atrophy. Psychiatry Clin Neurosci 2000;54:163-168.
28 Tatemichi TK, Desmond DW, Prohovnik I, Eidelberg D: Dementia associated with bilateral carotid occlusions: neuropsychological and haemodynamic course after extracranial to intracranial bypass surgery. J Neurol Neurosurg Psychiatry 1995;58:633-636.

29 Ariesen MJ, Claus SP, Rinkel GJ, Algra A: Risk factors for intracerebral hemorrhage in the general population: a systematic review. Stroke 2003;34:2060-2065.

30 Vinters HV: Cerebral amyloid angiopathy: a critical review. Stroke 1987;18:311-324.

31 Gray F, Chrétien F, Keohane C: Hereditary cerebral amyloid angiopathies. Rev Neurol (Paris) 2001;157:1207-1217.

32 Tzourio C, Dufouil C, Ducimetière P, Alperovitch $\mathrm{A}$ : Cognitive decline in individuals with high blood pressure: a longitudinal study in the elderly. EVA Study Group. Epidemiology of Vascular Aging. Neurology 1999;53:19481952.

33 Launer LJ, Ross GW, Petrovitch H, Masaki K, Foley D, White LR, Havlik RJ: Midlife blood pressure and dementia: the Honolulu-Asia aging study. Neurobiol Aging 2000;21:49-55. Moroney JT, Tang MX, Berglund L, Small S,
Merchant C, Bell K, Stern Y, Mayeux R: Lowdensity lipoprotein cholesterol and the risk of dementia with stroke. JAMA 1999;282:254260.

35 Zuliani G, Ble A, Zanca R, Munari MR, Zurlo A, Vavalle C, Atti AR, Fellin R: Lipoprotein profile in older patients with vascular dementia and Alzheimer's disease. BMC Geriatr 2001; 5.

36 Muckle TJ, Roy JR: High-density lipoprotein cholesterol in differential diagnosis of senile dementia. Lancet 1985;i:1191-1193.

37 Reitz C, Tang MX, Luchsinger J, Mayeux R: Relation of plasma lipids to Alzheimer disease and vascular dementia. Arch Neurol 2004;61: 705-714.

38 Juan D, Zhou DH, Li J, Wang JY, Gao C, Chen M: A 2-year follow-up study of cigarette smoking and risk of dementia. Eur J Neurol 2004; 11:277-282.

39 Ott A, Andersen K, Dewey ME, Letenneur L, Brayne C, Copeland JR, Dartigues JF, KraghSorensen P, Lobo A, Martinez-Lage JM, Stijnen T, Hofman A, Launer LJ: Effect of smoking on global cognitive function in nondemented elderly. Neurology 2004;62:920-924.

40 McIlroy SP, Dynan KB, Lawson JT, Patterson CC, Passmore AP: Moderately elevated plasma homocysteine, methylenetetrahydrofolate reductase genotype, and risk for stroke, vascular dementia, and Alzheimer disease in Northern Ireland. Stroke 2002;33:2351-2356.

41 Quadri P, Fragiacomo C, Pezzati R, Zanda E, Forloni G, Tettamanti M, Lucca U: Homocysteine, folate, and vitamin $B_{12}$ in mild cognitive impairment, Alzheimer disease, and vascular dementia. Am J Clin Nutr 2004;80:114-122.

42 Vermeer SE, van Dijk EJ, Koudstaal PJ, Oudkerk M, Hofman A, Clarke R, Breteler MM: Homocysteine, silent brain infarcts, and white matter lesions: the Rotterdam Scan Study. Ann Neurol 2002;51:285-289.
43 Prins ND, Den Heijer T, Hofman A, Koudstaal PJ, Jolles J, Clarke R, Breteler MM: Homocysteine and cognitive function in the elderly: the Rotterdam Scan Study. Neurology 2002;59:1375-1380.

44 Shumaker SA, Legault C, Rapp SR, Thal L, Wallace RB, Ockene JK, Hendrix SL, Jones BN III, Assaf AR, Jackson RD, Kotchen JM, Wassertheil-Smoller S, Wactawski-Wende J: Estrogen plus progestin and the incidence of dementia and mild cognitive impairment in postmenopausal women: the Women's Health Initiative Memory Study, a randomized controlled trial. JAMA 2003;289:2651-2662.

-45 Orgogozo JM, Dartigues JF, Lafont S, Letenneur L, Commenges D, Salamon R, Renaud S, Breteler MB: Wine consumption and dementia in the elderly: a prospective community study in the Bordeaux area. Rev Neurol (Paris) 1997; 153:185-192.

-46 Leibson CL, Rocca WA, Hanson VA, Cha R, Kokmen E, O'Brien PC, Palumbo PJ: The risk of dementia among persons with diabetes mellitus: a population-based cohort study. Ann NY Acad Sci 1997;826:422-427.

47 Messier C: Diabetes, Alzheimer's disease and apolipoprotein genotype. Exp Gerontol 2003; 38:941-946.

48 Alberts MJ: Genetics of cerebrovascular disease. Stroke 2004;35:342-344.

49 Knopman D, Boland LL, Mosley T, Howard G, Liao D, Szklo M, McGovern P, Folsom AR: Cardiovascular risk factors and cognitive decline in middle-aged adults. Neurology 2001; 56:42-48.

50 Hofman A, Ott A, Breteler MM, Bots ML, Slooter AJ, van Harskamp F, van Duijn CN, Van Broeckhoven C, Grobbee DE: Atherosclerosis, apolipoprotein E, and prevalence of dementia and Alzheimer's disease in the Rotterdam Study. Lancet 1997;349:151-154.

\51 Amarenco P, Cohen A, Tzourio C, Bertrand B, Hommel M, Besson G, Chauvel C, Touboul PJ, Bousser MG: Atherosclerotic disease of the aortic arch and the risk of ischemic stroke. N Engl J Med 1994;331:1474-1479.

52 Barnett HJ, Taylor DW, Eliasziw M, Fox AJ, Ferguson GG, Haynes RB, Rankin RN, Clagett GP, Hachinski VC, Sackett DL, Thorpe KE, Meldrum HE, Spence JD: Benefit of carotid endarterectomy in patients with symptomatic moderate or severe stenosis. North American Symptomatic Carotid Endarterectomy Trial Collaborators. N Engl J Med 1998; 339:1415-1425.

53 Prognosis of patients with symptomatic vertebral or basilar artery stenosis. The WarfarinAspirin Symptomatic Intracranial Disease (WASID) Study Group. Stroke 1998;29:1389_ 1392.

54 Kappelle LJ, Eliasziw M, Fox AJ, Sharpe BL, Barnett HJ: Importance of intracranial atherosclerotic disease in patients with symptomatic stenosis of the internal carotid artery. The North American Symptomatic Carotid Endarterectomy Trial. Stroke 1999;30:282-286. 
55 Vermeer SE, Den Heijer T, Koudstaal PJ, Oudkerk M, Hofman A, Breteler MM: Incidence and risk factors of silent brain infarcts in the population-based Rotterdam Scan Study. Stroke 2003;34:392-396.

-56 Pico F, Dufouil C, Levy C, Besançon V, de Kersaint-Gilly A, Bonithon-Kopp C, Ducimetière $\mathrm{P}$, Tzourio $\mathrm{C}$, Alperovitch $\mathrm{A}$ : Longitudinal study of carotid atherosclerosis and white matter hyperintensities: the EVA-MRI cohort. Cerebrovasc Dis 2002;14:109-115.

57 Traykov L, Rigaud AS, Baudic S, Smagghe A, Boller F, Forette F: Apolipoprotein E epsilon 4 allele frequency in demented and cognitively impaired patients with and without cerebrovascular disease. J Neurol Sci 2002;203-204: 177-181.

58 Pantoni L, Bianchi C, Beneke M, Inzitari D, Wallin A, Erkinjuntti T: The Scandinavian Multi-Infarct Dementia Trial: a double-blind, placebo-controlled trial on nimodipine in multi-infarct dementia. J Neurol Sci 2000; 175 : 116-123.

-59 Pantoni L, del Ser T, Soglian AG, Amigoni S, Spadari G, Binelli D, Inzitari D: Efficacy and safety of nimodipine in subcortical vascular dementia: a randomized placebo-controlled trial. Stroke 2005;36:619-624.

60 Wilkinson D, Doody R, Helme R, Taubman K, Mintzer J, Kertesz A, Pratt RD: Donepezil in vascular dementia: a randomized, placebocontrolled study. Neurology 2003;61:479486.

-61 Black S, Roman GC, Geldmacher DS, Salloway S, Hecker J, Burns A, Perdomo C, Kumar D, Pratt R: Efficacy and tolerability of donepezil in vascular dementia: positive results of a 24-week, multicenter, international, randomized, placebo-controlled clinical trial. Stroke 2003;34:2323-2330.
62 Erkinjuntti T, Kurz A, Gauthier S, Bullock R, Lilienfeld S, Damaraju CV: Efficacy of galantamine in probable vascular dementia and Alzheimer's disease combined with cerebrovascular disease: a randomised trial. Lancet 2002;359:1283-1290.

63 Devine ME, Rands G: Does aspirin affect outcome in vascular dementia? A retrospective case-notes analysis. Int $\mathrm{J}$ Geriatr Psychiatry 2003; 18:425-431.

64 Freels S, Nyenhuis DL, Gorelick PB: Predictors of survival in African American patients with $\mathrm{AD}, \mathrm{VaD}$, or stroke without dementia. Neurology 2002;59:1146-1153.

65 Forette F, Seux ML, Staessen JA, Thijs L, Birkenhager WH, Babarskiene MR, Babeanu S, Bossini A, Gil-Extremera B, Girerd X, Laks T, Lilov E, Moisseyev V, Tuomilehto J, Vanhanen H, Webster J, Yodfat Y, Fagard R: Prevention of dementia in randomised doubleblind placebo-controlled Systolic Hypertension in Europe (Syst-Eur) trial. Lancet 1998;352: 1347-1351.

66 PROGRESS Collaborative Group: Randomised trial of a perindopril-based bloodpressure-lowering regimen among 6,105 individuals with previous stroke or transient ischaemic attack. Lancet 2001;358:10331041.

67 Tzourio C, Anderson C, Chapman N, Woodward M, Neal B, MacMahon S, Chalmers J: Effects of blood pressure lowering with perindopril and indapamide therapy on dementia and cognitive decline in patients with cerebrovascular disease. Arch Intern Med 2003;163: 1069-1075.

68 Leys D: Atherothrombosis: a major health burden. Cerebrovasc Dis 2001;11(suppl 2):1-4.
69 Collaborative overview of randomised trials of antiplatelet therapy. 1. Prevention of death, myocardial infarction, and stroke by prolonged antiplatelet therapy in various categories of patients. Antiplatelet Trialists' Collaboration. BMJ 1994;308:81-106.

70 Harbison JW: Ticlopidine versus aspirin for the prevention of recurrent stroke: analysis of patients with minor stroke from the Ticlopidine Aspirin Stroke Study. Stroke 1992;23: 1723-1727.

71 Diener HC, Cunha L, Forbes C, Sivenius J, Smets P, Lowenthal A: European Stroke Prevention Study. 2. Dipyridamole and acetylsalicylic acid in the secondary prevention of stroke. J Neurol Sci 1996;143:1-13.

72 A randomised, blinded trial of clopidogrel versus aspirin in patients at risk of ischaemic events (CAPRIE). CAPRIE Steering Committee. Lancet 1996;348:1329-1339.

73 Voko Z, Koudstaal PJ, Bots ML, Hofman A, Breteler MM: Aspirin use and risk of stroke in the elderly: the Rotterdam Study. Neuroepidemiology 2001;20:40-44.

74 Elkind MS: The role of warfarin and aspirin in secondary prevention of stroke. Curr Cardiol Rep 2004;6:135-142.

75 van Dijk EJ, Prins ND, Vermeer SE, Koudstaal PJ, Breteler MM: Frequency of white matter lesions and silent lacunar infarcts. J Neural Transm Suppl 2002:25-39.

76 Vermeer SE, Hollander M, van Dijk EJ, Hofman A, Koudstaal PJ, Breteler MM: Silent brain infarcts and white matter lesions increase stroke risk in the general population: the Rotterdam Scan Study. Stroke 2003;34:11261129.

77 Albers GW, Amarenco P, Easton JD, Sacco RL, Teal P: Antithrombotic and thrombolytic therapy for ischemic stroke. Chest 2001;119: 300S-320S. 